\title{
Article \\ Nucleophilic Radiofluorination Using Tri-tert-Butanol Ammonium as a Bifunctional Organocatalyst: Mechanism and Energetics
}

\author{
Young-Ho Oh ${ }^{1}$, Sandip S. Shinde ${ }^{2, *}$ (i) and Sungyul Lee ${ }^{1, *}$ \\ 1 Department of Applied Chemistry, Kyung Hee University, Deogyeong-daero 1732, \\ Yongin-si 17104, Gyeonggi-do, Korea; chem_yhoh@daum.net \\ 2 Department of Nuclear Medicine, Molecular Imaging and Radiochemistry, Friedrich-Alexander University \\ Erlangen-Nürnberg (FAU), 91054 Erlangen, Germany \\ * Correspondence: shinde88@gmail.com (S.S.S.); sylee@khu.ac.kr (S.L.)
}

Citation: Oh, Y.-H.; Shinde, S.S.; Lee, S. Nucleophilic Radiofluorination Using Tri-tert-Butanol Ammonium as a Bifunctional Organocatalyst: Mechanism and Energetics. Molecules 2022, 27, 1044. https://doi.org/ $10.3390 /$ molecules 27031044

Academic Editor: Viktor O. Iaroshenko

Received: 28 December 2021

Accepted: 1 February 2022

Published: 3 February 2022

Publisher's Note: MDPI stays neutral with regard to jurisdictional claims in published maps and institutional affiliations.

Copyright: (C) 2022 by the authors. Licensee MDPI, Basel, Switzerland. This article is an open access article distributed under the terms and conditions of the Creative Commons Attribution (CC BY) license (https:// creativecommons.org/licenses/by/ $4.0 /)$.

\begin{abstract}
We present a quantum chemical analysis of the ${ }^{18}$ F-fluorination of 1,3-ditosylpropane, promoted by a quaternary ammonium salt (tri-(tert-butanol)-methylammonium iodide (TBMA-I) with moderate to good radiochemical yields (RCYs), experimentally observed by Shinde et al. We obtained the mechanism of the $\mathrm{S}_{\mathrm{N}} 2$ process, focusing on the role of the $-\mathrm{OH}$ functional groups facilitating the reactions. We found that the counter-cation $\mathrm{TBMA}^{+}$acts as a bifunctional promoter:

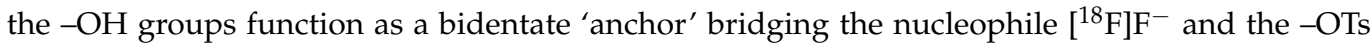
leaving group or the third $-\mathrm{OH}$. These electrostatic interactions cooperate for the formation of the transition states of a very compact configuration for facile $\mathrm{S}_{\mathrm{N}} 2{ }^{18} \mathrm{~F}$-fluorination.
\end{abstract}

Keywords: ${ }^{18}$ F-fluorination; tri-tert-butanol ammonium; organocatalysis; mechanism

\section{Introduction}

The ${ }^{18} \mathrm{~F}$-fluorination [1-20] of organic compounds is gaining considerable importance for synthesizing chemicals that can be employed as radiotracers for the diagnosis of various diseases [21-23] by the highly sensitive imaging technique of positron emission tomography (PET) [24,25]. Electrophilic substitution reactions [26-28] using the carrier added $\left[{ }^{18} \mathrm{~F}_{\mathrm{F}} \mathrm{F}_{2}\right.$ gas were the earlier method for this purpose, but this approach usually suffers from poor radiochemical yields (RCYs) and from the difficulty of handling the $\left.{ }^{18}{ }^{\mathrm{F}}\right] \mathrm{F}_{2}$ gas. The nucleophilic incorporation of $\left[{ }^{18} \mathrm{~F}\right]$ fluoride may be considered as a favorable alternative, but so far, this approach mainly requires azeotropic drying and multistep synthetic routes. Generally, this is undesirable for radiofluorination, as ${ }^{18} \mathrm{~F}$ possesses a relatively short half-life of $109.77 \mathrm{~min}$. Various non-radioactive nucleophilic fluorination methods [29-35] have been developed using various phase-transfer catalysts (PTCs) for their application in radiopharmaceutical chemistry in which hydrogen bonding between protic PTC and nucleophile $\left[{ }^{18} \mathrm{~F}\right]$ fluoride enhances the reaction and selectivity $[36,37]$. The recent development of tri-(tert-butanol)-methylammonium $\left[{ }^{18} \mathrm{~F}\right]$ fluoride (TBMA- ${ }^{18} \mathrm{~F}$ ) [13] as a promoter for radiofluorination demonstrated an excellent $\left[{ }^{18} \mathrm{~F}\right]$ fluoride elution efficiency under the reduced basicity of $\left[{ }^{18} \mathrm{~F}\right]$ fluoride, with moderate to good obtained RCYs. This technique seems to allow a single-step reaction scheme for the synthesis of ${ }^{18} \mathrm{~F}$-labeled substances, which would be a significant advance. Shinde and co-workers proposed that these excellent organocatalytic properties of the counter-cation may be attributed to the coordinating capacity of the two functional groups (ammonium and hydroxyl) in $\mathrm{TBMA}^{+}$. This rate enhancement, promoted by the counter-cation, which would be the first such example for ${ }^{18} \mathrm{~F}$-fluorination, exhibits significant advantages over more conventional methods using alkali metal cations, $\mathrm{M}^{+}(\mathrm{M}=\mathrm{K}, \mathrm{Rb}, \mathrm{Cs})$, because in the latter case the Lewis base promoters such as bulky alcohols [8,32], oligoethylene glycols [8,31,32], ionic liquids [8,33], or crown 
ethers $[34,35]$ are required to suppress the harmful Coulomb forces of the counter-cation on the nucleophile.

Here we elucidate the mechanism of the rate enhancement of ${ }^{18}$ F-fluorination by a quaternary ammonium salt (tri-(tert-butanol)-methylammonium iodide (TBMA-I)) (Scheme 1) by quantum chemical methods. We present the analysis of the ${ }^{18}$ Ffluorination of 1,3ditosylpropane (1), finding that the counter-cation $\mathrm{TBMA}^{+}$acts as a bifunctional promoter: the $-\mathrm{OH}$ groups in $\mathrm{TBMA}^{+}$act as a bidentate 'anchor' by forming hydrogen bonds with the nucleophilic $\left[{ }^{18} \mathrm{~F}\right]$ fluoride and the tosylate (-OTs) leaving group or the third $-\mathrm{OH}$. These electrostatic interactions cooperate for the formation of the transition state (TS) of a very compact configuration for facile $\mathrm{S}_{\mathrm{N}} 2{ }^{18} \mathrm{~F}$-fluorination. The fluorinating agent TBMA- ${ }^{18} \mathrm{~F}$ reacts with substrate 1 as a contact ion-pair, in which the counter-cation $\mathrm{TBMA}^{+}$and the nucleophile $\left[{ }^{18} \mathrm{~F}\right] \mathrm{F}^{-}$are in close contact.
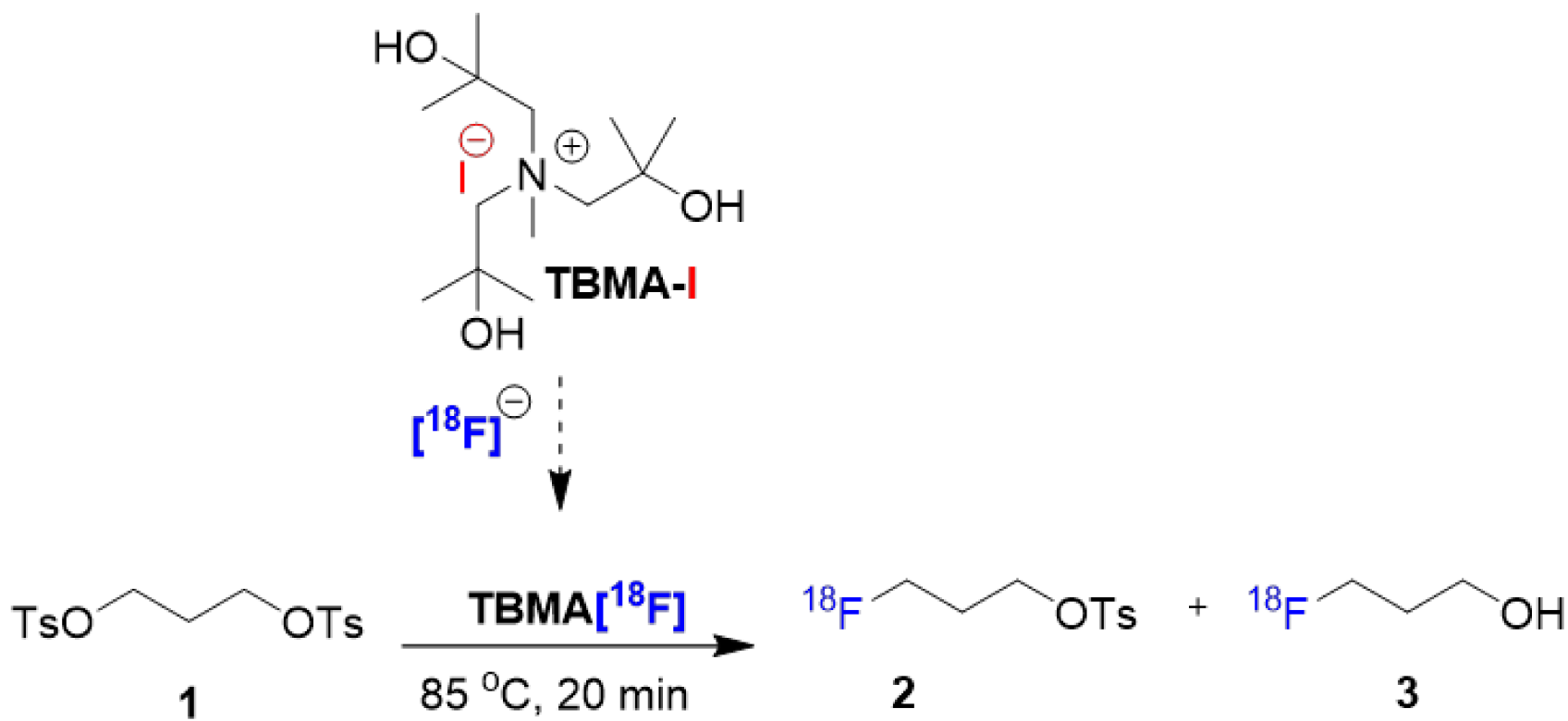

Scheme 1. Structure of TBMA-I and the ${ }^{18}$ F-fluorination of 1,3-ditosylpropane [13].

\section{Results}

Scheme 1 presents the structure of TBMA-I, which is transformed to TBMA- ${ }^{18} \mathrm{~F}$ by Shinde and co-workers' procedure [13], along with the ${ }^{18} \mathrm{~F}$-fluorination of the model substrate 1,3-ditosylpropane 1. Carrying out the reaction in $\mathrm{CH}_{3} \mathrm{CN}$ selectively produced the ${ }^{18}$ F-labeled product $\left[{ }^{18} \mathrm{~F}\right] 2$ with an RCY of $20 \%$ in $\mathrm{CH}_{3} \mathrm{CN}$ (Table 1). In Shinde and co-workers' experiments, TBMA- ${ }^{18} \mathrm{~F}$ is recovered from QMA cartridges after treatment with methanolic TBMA-I, and the counter-cation $\mathrm{TBMA}^{+}$accelerates the ${ }^{18}$ F-fluorination, thus the reaction given in Scheme 1 would be the key process.

Table 1. Reactivity of TBMA- ${ }^{18} \mathrm{~F}$ for ${ }^{18} \mathrm{~F}$-substitution of 1,3-ditosylpropane (1) [13].

\begin{tabular}{cccccc}
\hline Entry & Promoter & $\begin{array}{c}\text { Recovery of } \\
{\left[{ }^{18} \text { F fluoride }[\%]\right.}\end{array}$ & Solvent $(0.5 \mathrm{~mL})$ & \multicolumn{2}{c}{ RCY[\%] (Radio-TLC) } \\
\cline { 5 - 6 } & TBMA-I & 98.8 & $\mathrm{CH}_{3} \mathrm{CN}$ & 21 & $\left.\left[{ }^{\mathbf{1 8}} \mathrm{F}\right] \mathbf{2}\right] 3$ \\
\hline
\end{tabular}

Reactions were carried out using $15.0 \mu \mathrm{mol}$ of $(\mathbf{1}), \mathrm{K}_{2} \mathrm{CO}_{3}(1 \mathrm{M}, 15 \mu \mathrm{L})$, and $39.0 \mu \mathrm{mol}$ of TBMA-I at $85^{\circ} \mathrm{C}$ for
$20 \mathrm{~min}$.

We carried out density functional theory (DFT) calculations for the reaction in $\mathrm{CH}_{3} \mathrm{CN}$ and obtained the reaction mechanism and energetics shown in Figures 1 and 2, in which the TSs (structures of pre- and post-reaction complexes and Cartesian coordinates are listed in Supplementary Materials, Figure S1) and the energy profile are depicted. 


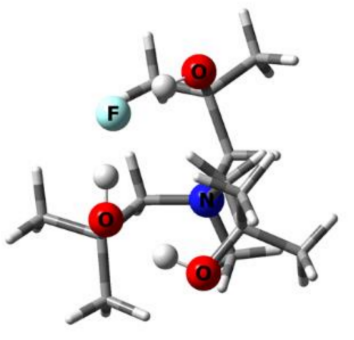

$\mathrm{TBMA}^{+} \mathrm{F}^{-}$

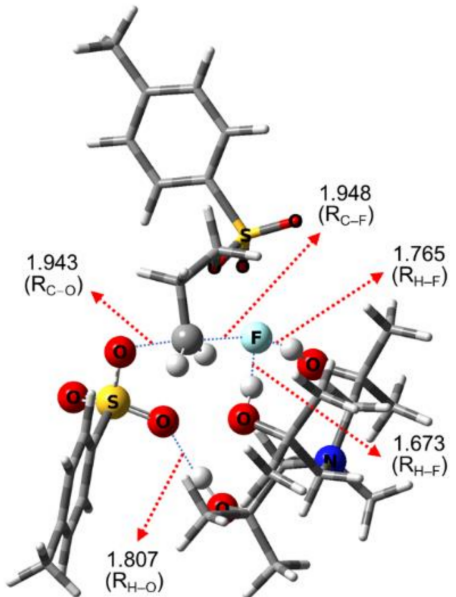

TS-S ${ }_{\mathrm{N}} 2{ }^{1}$

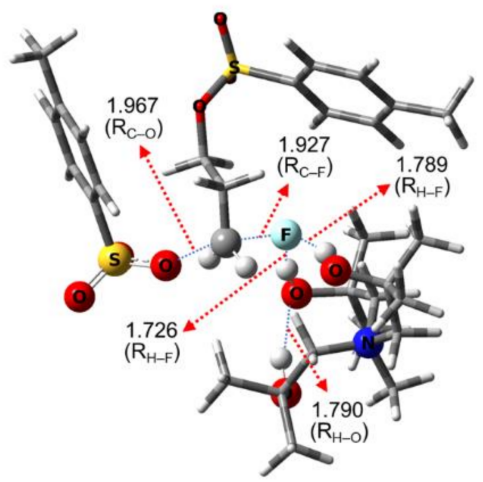

TS-S 2 2_2

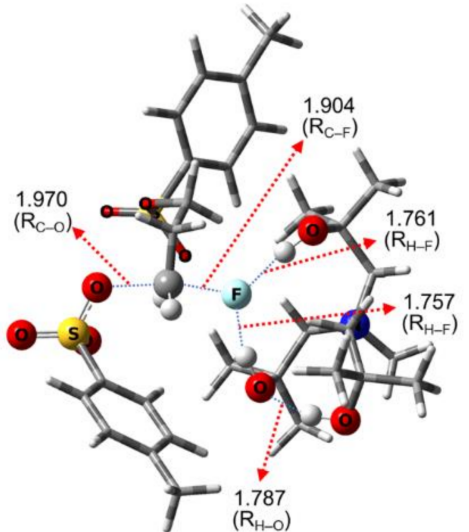

TS-S 2 2_3

Figure 1. Calculated structures of the free reactant $\mathrm{TBMA}^{+} \mathrm{F}^{-}$and the transition states of ${ }^{18} \mathrm{~F}-$ fluorination using TBMA- ${ }^{18} \mathrm{~F}$ in $\mathrm{CH}_{3} \mathrm{CN}$.

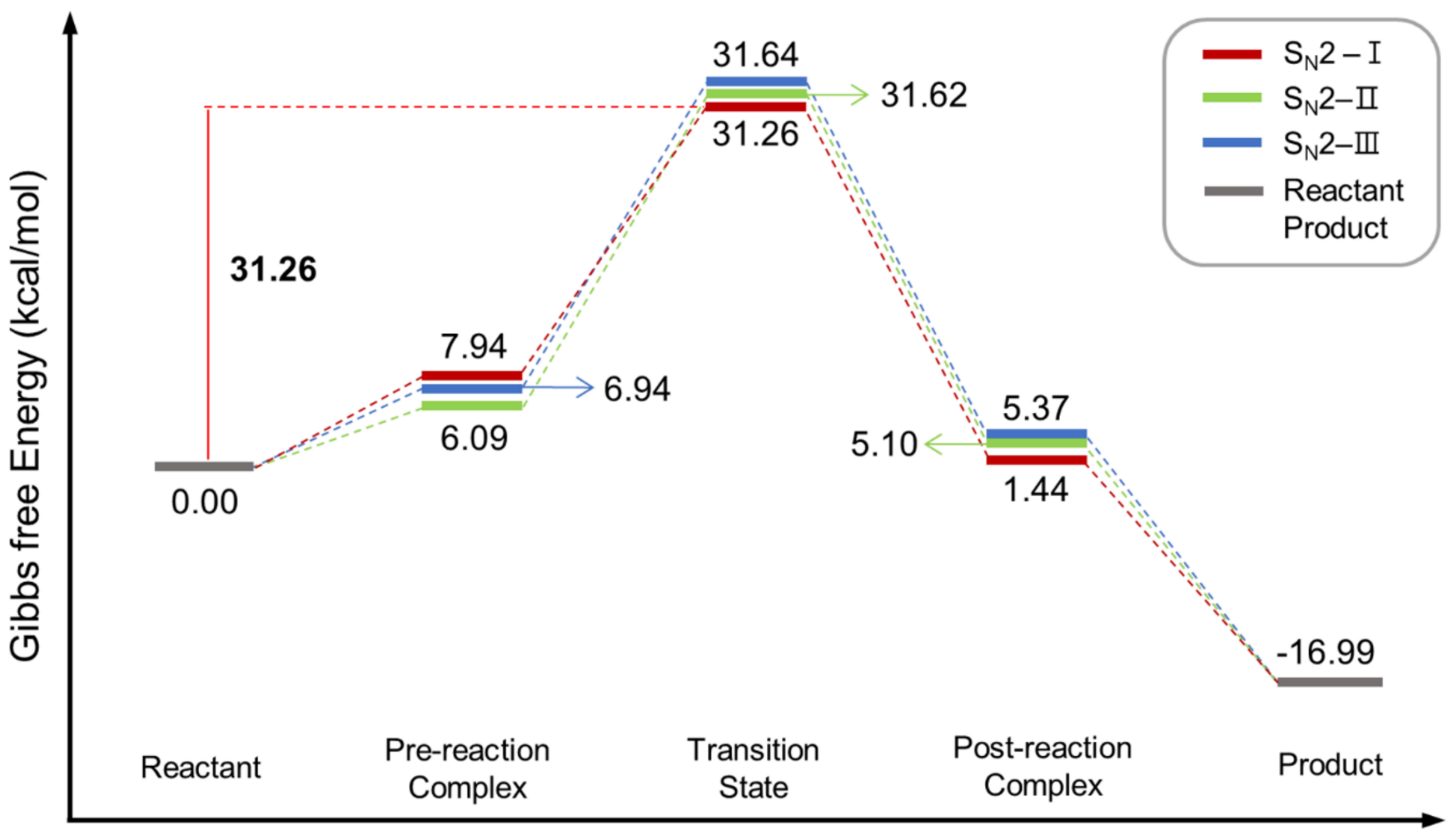

Reaction coordinate

Figure 2. Energetics of ${ }^{18} \mathrm{~F}$-fluorination using TBMA- ${ }^{18} \mathrm{~F}$ in $\mathrm{CH}_{3} \mathrm{CN}$.

We found three $\mathrm{S}_{\mathrm{N}} 2$ mechanisms with different TSs and energetics (Figure 1). In all TSs $\left(\mathrm{TS}-\mathrm{S}_{\mathrm{N}} 2 \_1, \mathrm{TS}-\mathrm{S}_{\mathrm{N}} 2 \_2, \mathrm{TS}-\mathrm{S}_{\mathrm{N}} 2 \_3\right)$, the ammonium $\mathrm{TBMA}^{+}$and the nucleophile $\left[{ }^{18} \mathrm{~F}\right] \mathrm{F}^{-}$are in close contact $\left(R_{\mathrm{N}-\mathrm{F}}=3.568-3.735 \AA\right)$, indicating that the reaction proceeds via the contact ion-pair (CIP) mechanism. In these TSs, hydrogen bonding between the two hydroxyl $-\mathrm{OHs}$, the third $-\mathrm{OH}$, or the tosylate (-OTs) leaving group are shown to play a crucial

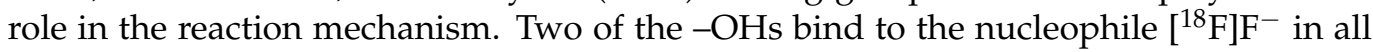
TSs. The role of the $3 \mathrm{rd}-\mathrm{OH}$, however, is somewhat different: in TS-S $\mathrm{N}_{2}{ }_{1}$, it interacts with the leaving group -OTs, assisting their departure, whereas in two other TSs, it forms 
a hydrogen bond with -OH. These electrostatic interactions help to form compact prereaction complexes and TSs (see Supplementary Materials, Figure S1) and TSs that are favorable for $\mathrm{S}_{\mathrm{N}} 2$ fluorination. Thus, the two $-\mathrm{OH}$ groups act as a bidentate 'anchor', and the counter-cation $\mathrm{TBMA}^{+}$plays its role as a promoter for the ${ }^{18} \mathrm{~F}$-fluorination by providing these two-OHs. The structures of the three TSs in Figure 1 are similar, the difference being in the relative orientation of the-OTs leaving group and $\mathrm{TBMA}^{+}$.

The relative feasibility of the three CIP mechanisms may be assessed by invoking the Curtin-Henderson principle [38]: if the transformation from free reactants to the prereaction complex is irreversible (that is, no equilibrium between the two), the reaction path with the lowest Gibbs free energy of the TS (that is, with lowest Gibbs free energy of activation $G^{\ddagger}$ with respect to the free reactants) is favored, irrespective of the Gibbs free energies of the pre-reaction complexes along the reaction routes. The calculated $G^{\ddagger}$ for the three reaction routes are $31.3,31.6$, and $31.6 \mathrm{kcal} / \mathrm{mol}$ (Figure 2), suggesting that they may contribute almost equally (the difference of $0.3 \mathrm{kcal}$ in $G^{\ddagger}$ for the case 1 and case 3 routes amounts to a 1:1.5 ratio of reaction rates at the reaction temperature of $85^{\circ} \mathrm{C}$ ).

It would be interesting to compare the mechanism of ${ }^{18} \mathrm{~F}$-fluorination by TBMA${ }^{18} \mathrm{~F}$ shown here with the mechanism [39] of promotion of (non-radiative) fluorination by [bmim][F] in a solvent-free environment, experimentally demonstrated by Magnier and co-workers [40]. In the latter process, the acidic $\mathrm{H}$-atom in the counter-cation bmim ${ }^{+}$ facilitates the detachment of the leaving group, whereas in the present case it is the -OHs interacting with the leaving group. It is to be noted that in both reactions the fluorinating agents (TBMA- $\left.{ }^{18} \mathrm{~F},[\mathrm{bmim}][\mathrm{F}]\right)$ act as promoters for the reactions as well. Strong Coulombic attraction between the nucleophile and the counter-cation forces them to react as a CIP.

The relative Gibbs free energies of the pre-reaction complexes in Figure 2, with respect to those of free reactants, are worth mentioning: the (stationary) pre-reaction complexes are predicted to lie higher than free reactants, in contrast with most $\mathrm{S}_{\mathrm{N}} 2$ reactions we have studied. Although some theoretical studies [41-43] have suggested that pre-reaction complexes could not be obtained in some cases, the origin of the 'well-skipping' $\mathrm{S}_{\mathrm{N}} 2$ reactions predicted here is not clear.

One of the salient features of Shinde and co-workers' procedure is that it produced the $\mathrm{S}_{\mathrm{N}} 2{ }^{18} \mathrm{~F}$-labeled product $\left[{ }^{18} \mathrm{~F}\right] 2$ exclusively, without $\mathrm{E} 2$ elimination [44] products, and this observation is worth mechanistic scrutiny. This aspect of Shinde's method is very important, because the exclusion of $\mathrm{E} 2$ products may be much more significant than the $\mathrm{S}_{\mathrm{N}} 2$ yield itself, especially for radiofluorination. Additional purification steps would be critically harmful when using the radiofluorinated product for clinical/diagnostic purposes due to the short lifetime of ${ }^{18} \mathrm{~F}$. Figures 3 and 4 present the two TSs (structures of pre- and post-reaction complexes and Cartesian coordinates are listed in Supplementary Materials, Figure S2) and the corresponding energetics, respectively, of the E2 elimination of $\mathbf{1}$ in $\mathrm{CH}_{3} \mathrm{CN}$. The Gibbs free energies of activation $G^{\ddagger}$ for the elimination process are calculated to be 34.1 35.5 $\mathrm{kcal} / \mathrm{mol}$ (Figure 4), which are considerably higher (by $2.8 \sim 4.2 \mathrm{kcal} / \mathrm{mol}$ ) than those for the $\mathrm{S}_{\mathrm{N}} 2{ }^{18} \mathrm{~F}$-fluorination (Figure 2), accounting for the experimentally observed exclusive formation of $\mathrm{S}_{\mathrm{N}} 2$ products. Thus, it seems that although the hydrogen bonding between the two $-\mathrm{OHs}$ and the nucleophile $\left[{ }^{18} \mathrm{~F}^{-} \mathrm{F}^{-}\right.$may retard the $\mathrm{S}_{\mathrm{N}} 2$ fluorination to a certain degree, these electrostatic interactions may also promote the reaction by facilitating the formation of a pre-reaction complex and TS that are much more advantageous for the $\mathrm{S}_{\mathrm{N}} 2$ over the E2 process. 


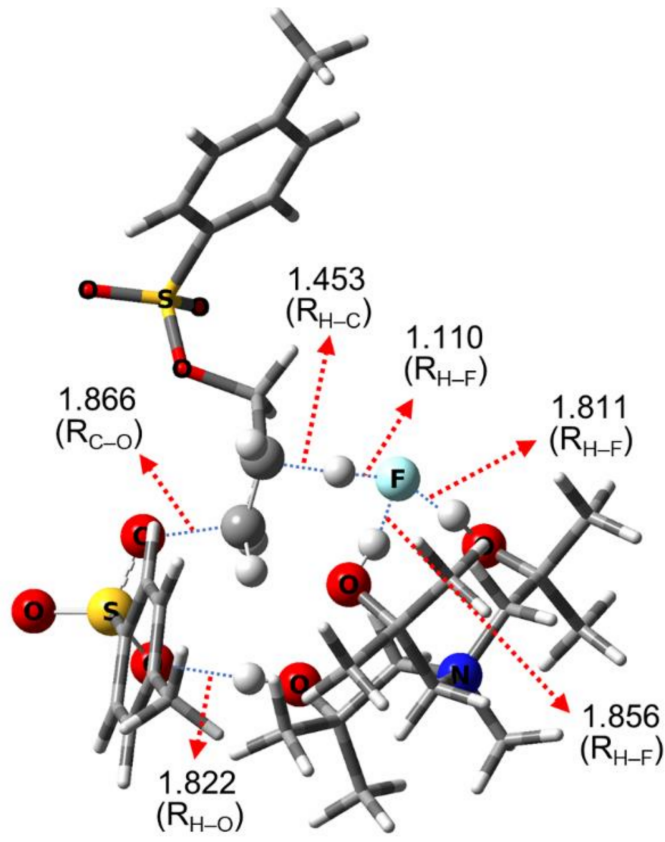

TS-E2_1

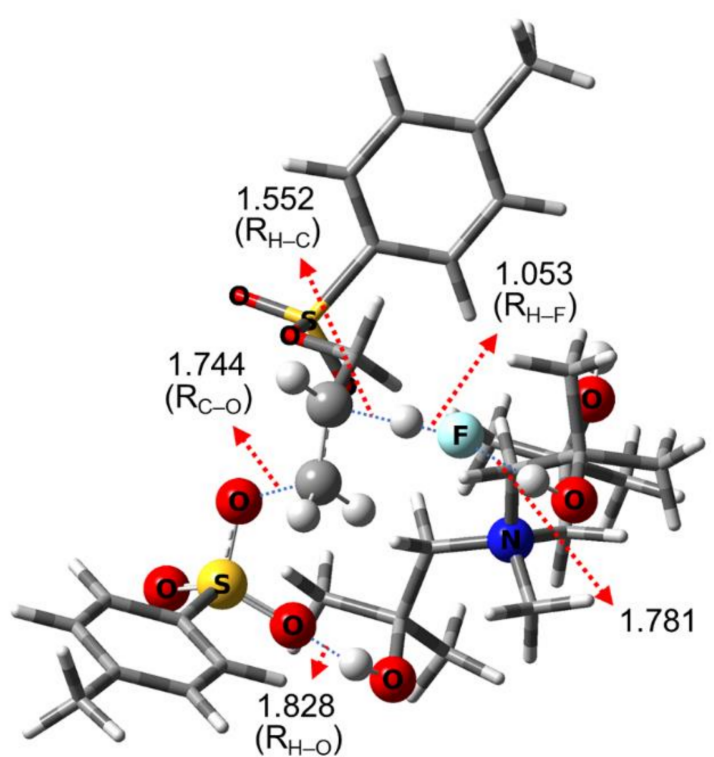

TS-E2_2

Figure 3. Calculated transition states of the E2 elimination of $\mathbf{1}$ in $\mathrm{CH}_{3} \mathrm{CN}$.

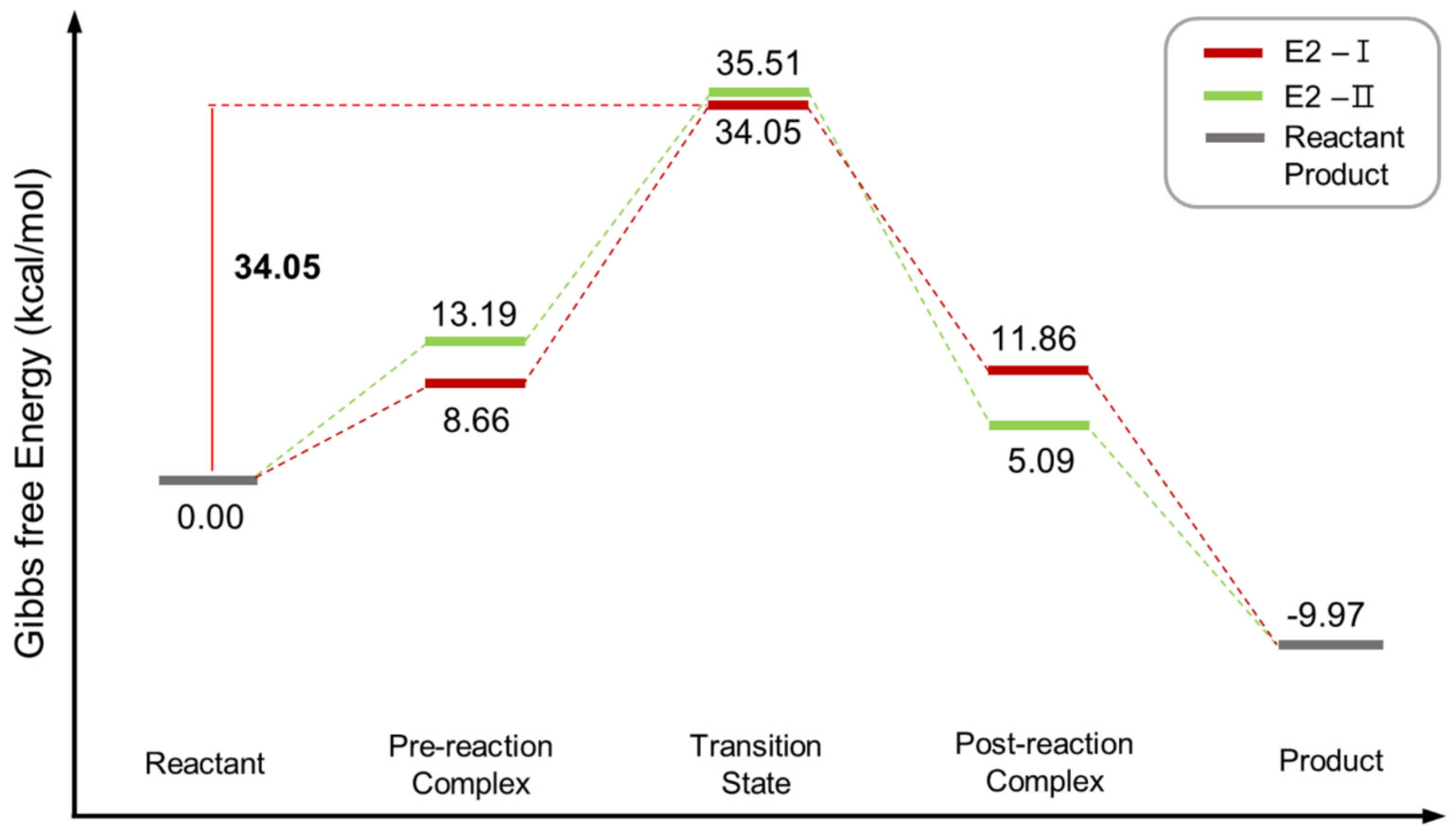

Reaction coordinate

Figure 4. Calculated energetics of the $\mathrm{E} 2$ elimination of 1 in $\mathrm{CH}_{3} \mathrm{CN}$.

\section{Computational Details}

The M06-2X/6-311G** method [45,46] was employed as implemented in Gaussian16 [47], which proved to be very instructive for treating non-covalent interactions [48]. We adopted the cluster/continuum approximation, including the effects of the solvent continuum by the SMD-PCM method [49]. The reference for the zero of the free energy is taken as the 'free' reactant, for which the substrate and TBMA- ${ }^{18} \mathrm{~F}$ are separated from each other in the 
solution phase. We carried out an extensive (but not exhaustive) search for stationary states over the potential energy surface of the system. Pre-reaction and post-reaction complexes were obtained by verifying that all harmonic frequencies are real. Transition states were obtained by ascertaining the imaginary frequency of the reaction coordinate, and also by performing the intrinsic reaction coordinate analysis.

\section{Conclusions}

We have presented the quantum chemical analysis to account for the activation of $\left[{ }^{18} \mathrm{~F}\right]$ fluoride by tri-(tert-butanol)-methylammonium. The role of the $-\mathrm{OH}$ in $\mathrm{TBMA}^{+}$as a bifunctional organocatalyst has been manifested: the hydroxyl groups function as a bidentate 'anchor' to position the nucleophile $\left[{ }^{18} \mathrm{~F}\right] \mathrm{F}^{-}$in a configuration suitable for the nucleophilic attack through hydrogen bonding. The elucidation of the underlying mechanism of the present $S_{\mathrm{N}} 2$ processes would help to drive the development of this technique forward, using better ammonium counter-cations (for example, those with other alcohol moieties containing $-\mathrm{OH}$, such as $-\mathrm{CH}_{2} \mathrm{OH}$, instead of $-t-\mathrm{BuOH}$ ) and schemes (for example, using a less bulky leaving group such as a mesylate, to have more beneficial interactions between the counter-cation and leaving group) for more efficient ${ }^{18}$ F-fluorination. The application of the present methodology to the nucleophilic radiofluorination of a variety of radiotracers would be highly desirable.

Supplementary Materials: Figure S1: Pre- and post-reaction complexes and the transition states of ${ }^{18} \mathrm{~F}$-fluorination using TBMA- ${ }^{18} \mathrm{~F}$ in $\mathrm{CH}_{3} \mathrm{CN}$; Figure S2: Pre- and post-reaction complexes and the transition states of $\mathrm{E} 2$ reactions using TBMA- ${ }^{18} \mathrm{~F}$ in $\mathrm{CH}_{3} \mathrm{CN}$.

Author Contributions: Conceptualization, S.L. and S.S.S.; methodology, Y.-H.O.; software, Y.-H.O.; formal analysis, S.L., S.S.S. and Y.-H.O.; investigation, Y.-H.O.; resources, S.L. and S.S.S.; writingoriginal draft preparation, Y.-H.O.; writing—review and editing, S.L. and S.S.S.; visualization, Y.-H.O.; project administration, S.L. and S.S.S.; funding acquisition, S.L. and S.S.S. All authors have read and agreed to the published version of the manuscript.

Funding: This research was funded by National Research of Korea (NRF-2019R1F1A1057609).

Institutional Review Board Statement: Not applicable.

Informed Consent Statement: Not applicable.

Data Availability Statement: Not applicable.

Conflicts of Interest: The authors declare no conflict of interest.

\section{References}

1. Lee, E.; Hooker, J.M.; Ritter, T. Nickel-mediated oxidative fluorination for PET with aqueous $\left[{ }^{18}\right.$ F] fluoride. J. Am. Chem. Soc. 2012, 134, 17456-17458. [CrossRef] [PubMed]

2. Tredwell, M.; Preshlock, S.M.; Taylor, N.J.; Gruber, S.; Huiban, M.; Passchier, J.; Mercier, J.; Génicot, C.; Gouverneur, V. A general copper-mediated nucleophilic ${ }^{18} \mathrm{~F}$ fluorination of arenes. Angew. Chemie 2014, 126, 7885-7889. [CrossRef]

3. Edwards, R.; Westwell, A.D.; Daniels, S.; Wirth, T. Convenient synthesis of diaryliodonium salts for the production of $\left[{ }^{18} \mathrm{~F}\right] \mathrm{F}-\mathrm{DOPA}$. European J. Org. Chem. 2015, 2015, 625-630. [CrossRef]

4. Wang, B.; Qin, L.; Neumann, K.D.; Uppaluri, S.; Cerny, R.L.; DiMagno, S.G. Improved arene fluorination methodology for I(III) salts. Org. Lett. 2010, 12, 3352-3355. [CrossRef]

5. Edwards, R.; Wirth, T. $\left[{ }^{18} \mathrm{~F}\right]$ 6-fluoro-3,4-dihydroxy-1-phenylalanine-recent modern syntheses for an elusive radiotracer. J. Label. Compd. Radiopharm. 2015, 58, 183-187. [CrossRef] [PubMed]

6. Pretze, M.; Wängler, C.; Wängler, B. 6- $\left[{ }^{18} \mathrm{~F}\right]$ fluoro-L-DOPA: A well-established neurotracer with expanding application spectrum and strongly improved radiosyntheses. Biomed Res. Int. 2014, 2014, 674063. [CrossRef]

7. Oh, Y.H.; Choi, H.; Lee, S.S.; Lee, S. Toward the Robust Synthesis of $\left[{ }^{18}\right.$ F]F-DOPA: Quantum Chemical Analysis of $\mathrm{S}_{\mathrm{N}}$ Ar Cold Fluorination of Diaryl Iodonium Salt by ${ }^{19} \mathrm{~F}^{-}$. Bull. Korean Chem. Soc. 2020, 41, 200-405. [CrossRef]

8. Lee, J.W.; Oliveira, M.T.; Jang, H.B.; Lee, S.; Chi, D.Y.; Kim, D.W.; Song, C.E. Hydrogen-bond promoted nucleophilic fluorination: Concept, mechanism and applications in positron emission tomography. Chem. Soc. Rev. 2016, 45, 4638-4650. [CrossRef]

9. Krasikova, R.N. Nucleophilic Synthesis of 6-1-[ $\left[{ }^{18} \mathrm{~F}\right]$ F-DOPA. Is Copper-Mediated Radiofluorination the Answer? Molecules 2020 25, 4365. [CrossRef] 
10. Maisonial-Besset, A.; Serre, A.; Ouadi, A.; Schmitt, S.; Canitrot, D.; Léal, F.; Miot-Noirault, E.; Brasse, D.; Marchand, P.; Chezal, J.M. Base/Cryptand/Metal-Free Automated Nucleophilic Radiofluorination of $\left[{ }^{18}\right.$ F]FDOPA from Iodonium Salts: Importance of Hydrogen Carbonate Counterion. European J. Org. Chem. 2018, 2018, 7058-7065. [CrossRef]

11. Zlatopolskiy, B.D.; Zischler, J.; Urusova, E.A.; Endepols, H.; Kordys, E.; Frauendorf, H.; Mottaghy, F.M.; Neumaier, B. A Practical One-Pot Synthesis of Positron Emission Tomography (PET) Tracers via Nickel-Mediated Radiofluorination. ChemistryOpen 2015, 4, 457-462. [CrossRef] [PubMed]

12. Jang, K.S.; Lee, S.S.; Oh, Y.H.; Lee, S.H.; Kim, S.E.; Kim, D.W.; Lee, B.C.; Lee, S.; Raffel, D.M. Control of reactivity and selectivity of guanidinyliodonium salts toward ${ }^{18} \mathrm{~F}$-Labeling by monitoring of protecting groups: Experiment and theory. J. Fluor. Chem. 2019, 227, 109387. [CrossRef]

13. Shinde, S.S.; Bolik, K.-V.; Maschauer, S.; Prante, O. ${ }^{18}$ F-Fluorination Using Tri-Tert-Butanol Ammonium Iodide as Phase-Transfer Catalyst: An Alternative Minimalist Approach. Pharmaceuticals 2021, 14, 833. [CrossRef] [PubMed]

14. Ichiishi, N.; Brooks, A.F.; Topczewski, J.J.; Rodnick, M.E.; Sanford, M.S.; Scott, P.J.H. Copper-catalyzed [ ${ }^{18}$ F]fluorination of (Mesityl)(aryl)iodonium salts. Org. Lett. 2014, 16, 3224-3227. [CrossRef]

15. Zischler, J.; Kolks, N.; Modemann, D.; Neumaier, B.; Zlatopolskiy, B.D. Alcohol-enhanced Cu-mediated radiofluorination. Chem. Eur. J. 2017, 23, 3251-3256. [CrossRef] [PubMed]

16. Stenhagen, I.S.R.; Kirjavainen, A.K.; Forsback, S.J.; Jørgensen, C.G.; Robins, E.G.; Luthra, S.K.; Solin, O.; Gouverneur, V. [ ${ }^{18}$ F] Fluorination of an arylboronic ester using $\left[{ }^{18} \mathrm{~F}\right]$ selectfluor bis (triflate): Application to $6-\left[{ }^{18} \mathrm{~F}\right]$ fluoro-l-DOPA. Chem. Commun. 2013, 49, 1386-1388. [CrossRef]

17. Makaravage, K.J.; Brooks, A.F.; Mossine, A.V.; Sanford, M.S.; Scott, P.J.H. Copper-mediated radiofluorination of arylstannanes with $\left[{ }^{18} \mathrm{~F}\right]$ KF. Org. Lett. 2016, 18, 5440-5443. [CrossRef]

18. Kuik, W.-J.; Kema, I.P.; Brouwers, A.H.; Zijlma, R.; Neumann, K.D.; Dierckx, R.A.J.O.; DiMagno, S.G.; Elsinga, P.H. In vivo biodistribution of no-carrier-added $6-{ }^{18} \mathrm{~F}$-fluoro-3, 4-dihydroxy-L-phenylalanine $\left({ }^{18} \mathrm{~F}\right.$-DOPA), produced by a new nucleophilic substitution approach, compared with carrier-added ${ }^{18} \mathrm{~F}$-DOPA, prepared by conventional electrophilic substitution. J. Nucl. Med. 2015, 56, 106-112. [CrossRef]

19. Inkster, J.A.H.; Akurathi, V.; Sromek, A.W.; Chen, Y.; Neumeyer, J.L.; Packard, A.B. A non-anhydrous, minimally basic protocol for the simplification of nucleophilic ${ }^{18} \mathrm{~F}$-fluorination chemistry. Sci. Rep. 2020, 10, 6818. [CrossRef]

20. Richarz, R.; Krapf, P.; Zarrad, F.; Urusova, E.A.; Neumaier, B.; Zlatopolskiy, B.D. Neither azeotropic drying, nor base nor other additives: A minimalist approach to ${ }^{18}$ F-labeling. Org. Biomol. Chem. 2014, 12, 8094-8099. [CrossRef]

21. Shinde, S.S.; Maschauer, S.; Prante, O. Sweetening Pharmaceutical Radiochemistry by ${ }^{18}$ F-Fluoroglycosylation: Recent Progress and Future Prospects. Pharmaceuticals 2021, 14, 1175. [CrossRef] [PubMed]

22. Minn, H.; Kauhanen, S.; Seppänen, M.; Nuutila, P. ${ }^{18}$ F-FDOPA: A multiple-target molecule. J. Nucl. Med. 2009, 50, 1915-1918. [CrossRef]

23. Morrish, P.K.; Sawle, G.V.; Brooks, D.J. Regional changes in $\left[{ }^{18} \mathrm{~F}\right]$ dopa metabolism in the striatum in Parkinson's disease. Brain 1996, 119, 2097-2103. [CrossRef]

24. Zhu, L.; Ploessl, K.; Kung, H.F. Expanding the scope of fluorine tags for PET imaging. Science 2013, 342, 429-430. [CrossRef]

25. Preshlock, S.; Tredwell, M.; Gouverneur, V. ${ }^{18}$ F-Labeling of Arenes and Heteroarenes for Applications in Positron Emission Tomography. Chem. Rev. 2016, 116, 719-766. [CrossRef]

26. Lee, E.; Kamlet, A.S.; Powers, D.C.; Neumann, C.N.; Boursalian, G.B.; Furuya, T.; Choi, D.C.; Hooker, J.M.; Ritter, T. A fluoridederived electrophilic late-stage fluorination reagent for PET imaging. Science 2011, 334, 639-642. [CrossRef] [PubMed]

27. Tredwell, M.; Gouverneur, V. ${ }^{18} \mathrm{~F}$ labeling of arenes. Angew. Chemie-Int. Ed. 2012, 51, 11426-11437. [CrossRef]

28. Wang, B.; Graskemper, J.W.; Qin, L.; DiMagno, S.G. Regiospecific reductive elimination from diaryliodonium salts. Angew. Chemie Int. Ed. 2010, 49, 4079-4083. [CrossRef]

29. Kim, D.W.; Jeong, H.; Lim, S.T.; Sohn, M. Tetrabutylammonium Tetra (tert-Butyl Alcohol)-Coordinated Fluoride as a Facile Fluoride Source. Angew. Chemie 2008, 120, 8532-8534. [CrossRef]

30. Boer, S.A.; Foyle, E.M.; Thomas, C.M.; White, N.G. Anion coordination chemistry using O-H groups. Chem. Soc. Rev. 2019, 48, 2596-2614. [CrossRef]

31. Lee, J.W.; Yan, H.; Jang, H.B.; Kim, H.K.; Park, S.W.; Lee, S.; Chi, D.Y.; Song, C.E. Bis-terminal hydroxy polyethers as all-purpose, multifunctional organic promoters: A mechanistic investigation and applications. Angew. Chemie-Int. Ed. 2009, 48, 7683-7686. [CrossRef]

32. Kim, D.W.; Ahn, D.S.; Oh, Y.H.; Lee, S.; Kil, H.S.; Oh, S.J.; Lee, S.J.; Kim, J.S.; Ryu, J.S.; Moon, D.H.; et al. A new class of S 2 reactions catalyzed by protic solvents: Facile fluorination for isotopic labeling of diagnostic molecules. J. Am. Chem. Soc. 2006, 128, 16394-16397. [CrossRef] [PubMed]

33. Kim, D.W.; Song, C.E.; Chi, D.Y. New method of fluorination using potassium fluoride in ionic liquid: Significantly enhanced reactivity of fluoride and improved selectivity. J. Am. Chem. Soc. 2002, 124, 10278-10279. [CrossRef] [PubMed]

34. Silva, S.L.; Valle, M.S.; Pliego Jr, J.R. Nucleophilic Fluorination with KF Catalyzed by 18-Crown-6 and Bulky Diols: A Theoretical and Experimental Study. J. Org. Chem. 2020, 85, 15457-15465. [CrossRef]

35. Oh, Y.-H.; Yun, W.; Kim, C.-H.; Jang, S.-W.; Lee, S.-S.; Lee, S.; Kim, D.-W. Inter- and intramolecular organo-catalysis of $\mathrm{S}_{\mathrm{N}} 2$ fluorination by crown ether: Kinetics and quantum chemical analysis. Molecules 2021, 26, 2947. [CrossRef] 
36. Shinde, S.S.; Khonde, N.S.; Kumar, P. Tri-tert-Butanolamine as an Organic Promoter in Nucleophilic Fluorination. ChemistrySelect 2017, 2, 118-122. [CrossRef]

37. Lee, S.-S.; Jung, H.-K.; Shinde, S.S.; Lee, S. Mechanistic study of nucleophilic fluorination promoted by tri-tert-butanolamine. J. Fluor. Chem. 2017, 197, 80-86. [CrossRef]

38. Seeman, J.I. The Curtin-Hammett principle and the Winstein-Holness equation: New definition and recent extensions to classical concepts. J. Chem. Educ. 1986, 63, 42. [CrossRef]

39. Choi, H.; Oh, Y.-H. Mechanism of promotion of $\mathrm{S}_{\mathrm{N}} 2$ fluorination by [Bmim]F in solvent-free environment: Quantum chemical analysis. Chem. Phys. Lett. 2020, 756, 137857. [CrossRef]

40. Bouvet, S.; Pegot, B.; Marrot, J.; Magnier, E. Solvent free nucleophilic introduction of fluorine with [bmim][F]. Tetrahedron Lett. 2014, 55, 826-829. [CrossRef]

41. Gao, Y.; Zhao, Y.; Guan, Q.; Wang, F. Ab initio kinetics predictions for the role of pre-reaction complexes in hydrogen abstraction from 2-butanone by OH radicals. RSC Adv. 2020, 10, 33205-33212. [CrossRef]

42. Dalessandro, E.V.; Pliego, J.R. Theoretical design of new macrocycles for nucleophilic fluorination with KF: Thiourea-crown-ether is predicted to overcome [2.2.2]-cryptand. Mol. Syst. Des. Eng. 2020, 5, 1513-1523. [CrossRef]

43. Dékány, A.Á.; Kovács, G.Z.; Czakó, G. High-Level Systematic Ab Initio Comparison of Carbon-and Silicon-Centered $\mathrm{S}_{\mathrm{N}} 2$ Reactions. J. Phys. Chem. A 2021, 125, 9645-9657. [CrossRef]

44. Liu, X.; Zhang, L.; Yang, L.; Hase, W.L. How a Solvent Molecule Affects Competing Elimination and Substitution Dynamics. Insight into Mechanism Evolution with Increased Solvation. J. Am. Chem. Soc. 2018, 140, 10995-11005. [CrossRef]

45. Zhao, Y.; Truhlar, D.G. The M06 suite of density functionals for main group thermochemistry, thermochemical kinetics, noncovalent interactions, excited states, and transition elements: Two new functionals and systematic testing of four M06-class functionals and 12 other function. Theor. Chem. Acc. 2008, 120, 215-241. [CrossRef]

46. Krishnan, R.; Binkley, J.S.; Seeger, R.; Pople, J.A. Self-consistent molecular orbital methods. XX. A basis set for correlated wave functions. J. Chem. Phys. 1980, 72, 650-654. [CrossRef]

47. Frisch, M.J.; Trucks, G.W.; Schlegel, H.B.; Scuseria, G.E.; Robb, M.A.; Cheeseman, J.R.; Scalmani, G.; Barone, V.; Petersson, G.A.; Nakatsuji, N.; et al. Gaussian 16; Revision A.03; Gaussian, Inc.: Wallingford, CT, USA, 2016.

48. Hohenstein, E.G.; Chill, S.T.; Sherrill, C.D. Assessment of the performance of the M05- 2X and M06-2X exchange-correlation functionals for noncovalent interactions in biomolecules. J. Chem. Theory Comput. 2008, 4, 1996-2000. [CrossRef]

49. Marenich, A.V.; Cramer, C.J.; Truhlar, D.G. Universal solvation model based on solute electron density and on a continuum model of the solvent defined by the bulk dielectric constant and atomic surface tensions. J. Phys. Chem. B 2009, 113, 6378-6396. [CrossRef] [PubMed] 